\title{
Commentary: The Spinal Cord Has an Intrinsic System for the Control of pH
}

\author{
Joseph M. Santin ${ }^{1 *}$, Tobias Wang ${ }^{2}$, Saihari S. Dukkipati ${ }^{3}$ and Lynn K. Hartzler ${ }^{1}$ \\ ${ }^{1}$ Department of Biological Sciences, Wright State University, Dayton, OH, USA, ${ }^{2}$ Department of Bioscience, Zoophysiology, \\ Aarhus University, Aarhus, Denmark, ${ }^{3}$ Department of Neuroscience, Cell Biology, and Physiology, Wright State University, \\ Dayton, $\mathrm{OH}$, USA
}

Keywords: pH, spinal cord, temperature, alpha-stat, CSF-c neuron

\section{A commentary on}

The Spinal Cord Has an Intrinsic System for the Control of $\mathbf{p H}$

by Jalalvand, E., Robertson, B., Tostivint, H., Wallén, P., and Grillner, S. (2016). Curr. Biol. 26, 1346-1351. doi: 10.1016/j.cub.2016.03.048

Most physiological processes are sensitive to $\mathrm{pH}$ (i.e., hydrogen ion activity) and regulation of $\mathrm{pH}$ within tissues and body fluids represents a fundamental homeostatic process in living organisms. At the organismal level, acid-base balance is achieved by fast respiratory modulations of the partial pressure of $\mathrm{CO}_{2}$ in combination with slower transepithelial ion movements to accommodate

OPEN ACCESS

Edited by:

David Fuller,

University of Florida, USA

Reviewed by:

Stephen M. Johnson,

University of Wisconsin-Madison, USA

David M. Baekey,

University of Florida College of Veterinary Medicine, USA

*Correspondence:

Joseph M. Santin

santin.2@wright.edu

Specialty section:

This article was submitted to Respiratory Physiology, a section of the journal Frontiers in Physiology

Received: 07 September 2016 Accepted: 19 October 2016 Published: 07 November 2016

Citation: Santin JM, Wang T, Dukkipati SS and Hartzler LK (2016) Commentary: The Spinal Cord Has an Intrinsic System for the Control of $\mathrm{pH}$. Front. Physiol. 7:513 doi: 10.3389/fphys.2016.00513 excretion and retention of bicarbonate and protons in response to acid-base disturbances. At the cellular and subcellular levels, acid-base balance is achieved by ion exchange.

Recently in Current Biology, Jalalvand et al. (2016) described a novel pH sensing system in the spinal cord of lampreys with an ability to inhibit locomotor activity. This system involves inhibitory spinal neurons in intimate contact with the cerebrospinal fluid, termed CSF-c neurons that increase firing frequencies whenever $\mathrm{pH}$ deviates in either direction from 7.4. Due to their inhibitory nature, activation of the CSF-c neurons decreases locomotor activity when $\mathrm{pH}$ strays above and below 7.4. This presents a unique and unusual mechanism whereby extracellular $\mathrm{pH}$ exerts direct regulation of locomotor activity. The authors conclude that this sensory system represents a "novel innate homeostatic mechanism, designed to sense any deviation from physiological $\mathrm{pH}$ and to respond by causing a depression of the motor activity" (Jalalvand et al., 2016). In the following, we argue that the $\mathrm{pH}$ sensory system uncovered by Jalalvand et al. does not support this conclusion because the $\mathrm{pH}$ of 7.4-interpreted as the control condition-is incorrect for ectothermic animals, such as lampreys when studied at low body temperature (Wang and Jackson, 2016).

The authors erroneously assume that a superfusate $\mathrm{pH}$ of 7.4 mimics the normal $\mathrm{pH}$ of body fluids in ectotherms at $8-10^{\circ} \mathrm{C}$, the temperature where the in vitro spinal cord was studied. While mammals regulate arterial blood $\mathrm{pH}\left(\mathrm{pH}_{\mathrm{a}}\right)$ at 7.4 at their normal body temperature of $37^{\circ} \mathrm{C}$, Jalalvand et al. (2016) ignore that both $\mathrm{pH}_{\mathrm{a}}$ and $\mathrm{CSF} \mathrm{pH}\left(\mathrm{pH}_{\mathrm{CSF}}\right)$ increase by $\sim 0.015$ unit per ${ }^{\circ} \mathrm{C}$ when body temperature decreases in ectothermic vertebrates (Burton, 2002). This so-called alphastat regulation serves to maintain protein ionization (Reeves, 1977), and explains why the normal and regulated $\mathrm{pH}_{\mathrm{a}}$ of the closely related sea lamprey, Petromyzon marinus, is $\sim 8.1$ at 8 $10^{\circ} \mathrm{C}$ (Tufts et al., 1992). As a consequence, the control value of 7.4 used by Jalalvand et al. is highly acidic, even when compared with maximal acidosis $\left(\mathrm{pH}_{\mathrm{a}}\right.$ 7.7) upon intense and exhaustive exercise (Tufts et al., 1992). Ectothermic vertebrates, including aquatic species, have $\mathrm{pH}_{\mathrm{CSF}}$ values $\sim 0.1-0.2$ $\mathrm{pH}$ units lower than $\mathrm{pH}_{\mathrm{a}}$ at low temperatures (Hitzig, 1982; Wood et al., 1990). Assuming a $\mathrm{pH}_{\mathrm{a}}$ value of $\sim 8.1, \mathrm{pH}_{\mathrm{CSF}}$ should be $\sim 7.9$ in resting lampreys.

The much higher in vivo $\mathrm{pH}$ than that used in the in vitro experiments completely alters the interpretation of the "U-shaped curve" with minimum firing frequencies of CSF-c neurons at 7.4 
(Jalalvand et al., 2016). Rather than demonstrating minimum CSF-c neuron activity at resting in vivo $\mathrm{pH}$ values, the true resting values are, in fact, on the right-hand side of ascending part of the "U" (see Figure $4 \mathrm{~F}$ of Jalalvand et al., 2016). CSF-c neurons, therefore, offer no protective or homeostatic influence by minimizing locomotion when $\mathrm{pH}$ deviates in either direction from its resting value because a realistic acidosis of fluid in contact with these neurons would decrease inhibitory tone of the locomotor network, and hence increase locomotion.

We propose that CSF in the lamprey would be less acidic in vivo compared to the in vitro conditions used by Jalalvand et al. and this also applies to the $\mathrm{pH}$ of the interstitial fluid $\left(\mathrm{pH}_{\mathrm{ins}}\right)$ that interfaces with neuronal membranes. Chesler (1986) showed the lamprey brain in vitro has a $\mathrm{pH}_{\mathrm{ins}}$ of 7.3-7.4 when bathed at 7.8 at $23^{\circ} \mathrm{C}$, a control $\mathrm{pH}$ that is slightly acidic, but more appropriate than 7.4 for aquatic ectotherms (Wood et al., 1990). Thus, $\mathrm{pH}_{\text {ins }}$ values near $\sim 7.5$ would be expected if the control bathing solution had a correct $\mathrm{pH}$ of $\sim 7.9$. A large interstitial acidosis relative to the superfusate is anticipated in vitro since these preparations lack blood flow to remove metabolically produced $\mathrm{CO}_{2}$. Accordingly, $\mathrm{pH}_{\text {ins }}$ in vivo typically rest only $\sim 0.1-0.2 \mathrm{pH}$ unit below $\mathrm{pH}_{\mathrm{a}}$ (Kraig et al., 1983). If we interpret the bathinterstitial $\mathrm{pH}$ difference observed in vitro as being, at least in part, physiological, this translates to $\mathrm{pH}_{\text {ins }}$ values of $\sim 7.0$, as measured by Chesler (1986), in contact with CSF-c neurons in the experiments by Jalalvand et al. Minimum frequencies of CSFc neurons, therefore, center on a highly acidic $\mathrm{pH}_{\text {ins }}$ instead of a more alkaline value expected for lamprey. Since minimum frequencies of CSF-c neurons occur at acidic values, this sensor might, instead, operate normally along an alkaline-activated and acid-inhibited slope that increases locomotor burst frequency during physiological acidification.

Jalalvand et al. did not state whether CSF-c neurons sample CSF or interstitial $\mathrm{pH}$, making it unclear which compartment

\section{REFERENCES}

Burton, R. F. (2002). Evolutionary determinants of normal arterial plasma $\mathrm{pH}$ in ectothermic vertebrates. J. Exp. Biol. 205, 641-650.

Chesler, M. (1986). Regulation of intracellular $\mathrm{pH}$ in reticulospinal neurones of the lamprey, Petromyzon marinus. J. Physiol. 381, 241-261. doi: 10.1113/jphysiol.1986.sp016325

Chesler, M. (2003). Regulation and modulation of $\mathrm{pH}$ in the brain. Physiol. Rev. 83, 1183-1221. doi: 10.1152/physrev.00010.2003

Hitzig, B. M. (1982). Temperature-induced changes in turtle CSF pH and central control of ventilation. Respir. Physiol. 49, 205-222. doi: 10.1016/00345687(82)90074-3

Jalalvand, E., Robertson, B., Tostivint, H., Wallén, P., and Grillner, S. (2016). The spinal cord has an intrinsic system for the control of pH. Curr. Biol. 26, 1346-1351. doi: 10.1016/j.cub.2016.03.048

Kraig, R. P., Ferreira-Filho, C. R., and Nicholson, C. (1983). Alkaline and acid transients in cerebellar microenvironment. J. Neurophysiol. 49, $831-850$.

Reeves, R. B. (1977). The interaction of body temperature and acid-base balance in ectothermic vertebrates. Annu. Rev. Physiol. 39, 559-586. doi: 10.1146/annurev.ph.39.030177.003015 might have its $\mathrm{pH}$ controlled through $\mathrm{pH}$ sensing in CSFc neurons and subsequent alterations in locomotion. Nor did they report what in vivo $\mathrm{pH}$ set points should be for any of these compartments. Disturbances in $\mathrm{pH}_{\text {ins }}$ arise during neuronal activity (Chesler, 2003), implying that CSF-c neurons could function on a slope within the physiological range. In contrast, it is less obvious what scenarios may change $\mathrm{pH}_{\mathrm{CSF}}$ to alter firing rates of CSF-c neurons because metabolic acid-base disturbances are unlikely to alter $\mathrm{pH}_{\mathrm{CSF}}$, at least in the short term, because the CSF is separated by the blood-brain barrier.

As articulated by Reeves (1977), "The very large number of investigations that uncritically used $\mathrm{pH} 7.4$ for Ringer's solutions at any temperature in experiments on frog and other ectothermic tissue attests to how cherished misinformation can be even in the scientific community." Until experiments are performed to clarify which compartments' $\mathrm{pH}$ may be determined by $\mathrm{pH}$ sensing in CSF-c neurons and under what conditions this sensor operates, it remains disputable that CSF-c neurons provide an "innate homeostatic mechanism" by inhibiting locomotion during deviations from physiological $\mathrm{pH}$.

\section{AUTHOR CONTRIBUTIONS}

JS, TW, SD, and LH interpreted results; JS wrote the manuscript; JS, TW, SD, and LH edited, revised, and approved final manuscript.

\section{FUNDING}

We would like to thank the Wright State University Biomedical Sciences Ph.D. Program (JS), the Danish Natural Sciences Research Council (FNU) (TW), the National Institutes of HealthNS091836 to Sherif Elbasiouny (SD), and the National Science Foundation IOS-1257338 (LH) for funding.
Tufts, B., Bagatto, B., and Cameron, B. (1992). In vivo analysis of gas transport in arterial and venous blood of the sea lamprey Petromyzon marinus. J. Exp. Biol. $169,105-119$.

Wang, T., and Jackson, D. C. (2016). How and why $\mathrm{pH}$ changes with body temperature: the $\alpha$-stat hypothesis. J. Exp. Biol. 219, 1090-1092. doi: $10.1242 /$ jeb. 139220

Wood, C., Turner, J., Munger, R., and Graham, M. S. (1990). Control of ventilation in the hypercapnic skate Raja ocellata: II. Cerebrospinal fluid and intracellular $\mathrm{pH}$ in the brain and other tissues. Respir. Physiol. 80, 279-297. doi: 10.1016/0034-5687(90)90089-H

Conflict of Interest Statement: The authors declare that the research was conducted in the absence of any commercial or financial relationships that could be construed as a potential conflict of interest.

Copyright (c) 2016 Santin, Wang, Dukkipati and Hartzler. This is an open-access article distributed under the terms of the Creative Commons Attribution License (CC $B Y)$. The use, distribution or reproduction in other forums is permitted, provided the original author(s) or licensor are credited and that the original publication in this journal is cited, in accordance with accepted academic practice. No use, distribution or reproduction is permitted which does not comply with these terms. 